PACS 31.15.-p; 33.20.-t

Kirianov S. V., Mashkantsev A. A., Bilan I. I., Ignatenko A. V.

Odesa State Environmental University, 15, L’vovskaya str., Odesa, 65016

E-mail: kirianovserg@gmail.com

\title{
DYNAMICAL AND TOPOLOGICAL INVARIANTS OF NONLINEAR DYNAMICS OF THE CHAOTIC LASER DIODES WITH AN ADDITIONAL OPTICAL INJECTION
}

\begin{abstract}
Nonlinear chaotic dynamics of the of the chaotic laser diodes with an additional optical injection is computed within rate equations model, based on the a set of rate equations for the slave laser electric complex amplitude and carrier density. To calculate the system dynamics in a chaotic regime the known chaos theory and non-linear analysis methods such as a correlation integral algorithm, the Lyapunov's exponents and Kolmogorov entropy analysis are used. There are listed the data of computing dynamical and topological invariants such as the correlation, embedding and Kaplan-Yorke dimensions, Lyapunov's exponents, Kolmogorov entropy etc. New data on topological and dynamical invariants are computed and firstly presented.
\end{abstract}

\section{Introduction}

The elements of chaotic dynamics in different laser systems and devices, including semiconductor lasers, laser diodes, resonators etc are of a great importance and interest because of their potential applications in laser physics and quantum electronics, optical secure communications and cryptography, and many others. At the same time, the laser's relaxation oscillation limits the bandwidth of chaotic light emitted from a laser diode and similar devices with single optical injection or feedback. This circumstance as well as a general interest to new theoretical dynamics phenomena make necessary the further studying and improvement the main features of the optical chaos communications.

. From the other side, there is a general interest to studying the chaotic laser systems provided a necessity of the further development of a general theory of dynamic systems and a chaos.

Let us remind that according to Refs. [115], under the definite conditions, such systems are described by the corresponding model, when Hamiltonians are possessing only a few degrees of freedom. For the lowdimensional chaotic case the corresponding conditions of transition to deterministic chaos in the system dynamics are quite well understood at the classical level [1-4].
Under quantum treatment of the problem, the similar systems (in particular, the diatomic molecules in a resonant electromagnetic field) are studied with using the known quasiclassical approach [2]. At the theoretical level, the majority of studies, devoted to chaos phenomena in molecular dynamics, is carried out with the using simple tools of dynamical systems theory and qualitative theory of differential equations. New field of investigations of the quantum and other systems has been provided by the known progress in a development of a nonlinear analysis and chaos theory methods [1-12,17-30].

In Refs. [11,27-33] the authors applied different approaches to quantitative studying regular and chaotic dynamics of atomic and molecular systems interacting with a strong electromagnetic field and laser systems.

The most popular approach to studying nonlinear dynamics of chaotic systems includes the combined using the advanced nonlinear analysis and a chaos theory methods such as the autocorrelation function method, multi-fractal formalism, mutual information approach, correlation integral analysis, false nearest neighbour algorithm, Lyapunov exponent's analysis, surrogate data method, stochastic propagators method, memory and Green's functions approaches etc (see details in Refs. [17-24]). 
In Ref. [1] the authors experimentally and numerically demonstrate the route to band width enhanced chaos in a chaotic laser diode with an additional optical injection; they used the own unique experimental setup, which includes a distributed feedback (DFB) laser with a $4 \mathrm{~m}$ fiber ring feedback cavity (the slave laser) and the other solitary DFB laser as an injection laser (the master laser) to enlarge the bandwidth of the chaotic laser (see detailed description in Ref. [1]). The concrete technological characteristics are as follows: slave laser is biased at $28.0 \mathrm{~mA}$ (1.27 times threshold), and its wavelength is stabilized at $1553.8 \mathrm{~nm}$ with $0.3 \mathrm{~nm}$ linewidth (at $-20 \mathrm{~dB}$ ) and a $35 \mathrm{~dB}$ side mode suppression ratio; respectively, the laser's output power is $0.7 \mathrm{~mW}$, and the relaxation frequency and modulation bandwidth were about $2 \mathrm{GHz}$ and $5 \mathrm{GHz}$. The original set of the chaotic states before optical injection is obtained with $-6.1 \mathrm{~dB}$ optical feedback (the feedback injection strength with a scale of the solitary slave laser's power).

In this paper we present the corresponding results of computing the characteristic dynamical and topological invariants of the nonlinear dynamics of the chaotic laser diode with an additional optical injection (all characteristics are corresponding to parameters of the Ref. [1]).

\section{Chaos-geometric approach to dy- namics of the chaotic systems}

As the main ideas of the quantumdynamic approach to diatomic molecule in an electromagnetic field are in details presented in the Refs. [5-7,2], here we will restrict yourself only by some necessary elements.

In order to perform the detailed analysis of the chaotic regime polarization time series, further a total dynamics of the quantum system in an electromagnetic field and to calculate the fundamental topological and dynamical invariants of the system in a chaotic regime we used the universal chaos-geometric approach, presented earlier (see, c.g., [5-7,19-20]).
Generally speaking, the approach includes a set of such non-linear analysis and a chaos theory methods as the correlation integral approach, multi-fractal and wavelet analysis, average mutual information, surrogate data, Lyapunov's exponents and Kolmogorov entropy approach, spectral methods, nonlinear prediction (predicted trajectories, neural network etc) algorithms.

One of the important tasks here is to determine the corresponding embedding dimension and to reconstruct a Euclidean space $R^{d}$ large enough so that the set of points $d_{A}$ can be unfolded without ambiguity. In accordance with the embedding theorem, the embedding dimension, $d_{E}$, must be greater, or at least equal, than a dimension of attractor, $d_{A}$, i.e. $d_{E}>d_{A}$.

Usually one should use several standard approaches to reconstruction of the attractor dimension (see, e.g., [17-20]). The correlation integral analysis is one of the widely used techniques to investigate the signatures of chaos in a time series. The analysis uses the correlation integral, $C(r)$, to distinguish between chaotic and stochastic systems.

To compute the correlation integral, the algorithm of Grassberger and Procaccia is the most commonly used approach. According to this algorithm, the correlation integral is

$$
C(r)=\lim _{N \rightarrow \infty} \frac{2}{N(n-1)} \sum_{\substack{i, j \\(1 \leq i<j \leq N)}} H\left(r-\left\|\mathbf{y}_{i}-\mathbf{y}_{j}\right\|\right)
$$

where $H$ is the Heaviside step function with $H(u)=1$ for $u>0$ and $H(u)=0$ for $u \leq 0, r$ is the radius of sphere centered on $\mathbf{y}_{i}$ or $\mathbf{y}_{j}$, and $N$ is the number of data measurements.

In order to perform the verification of the results obtained by means of the correlation integral analysis, one could use so called known surrogate data method. This approach makes use of the substitute data generated in accordance to the probabilistic structure underlying the original data.

The important dynamical invariants of a chaotic system are the Lyapunov's exponents (see, c.g., [17-20]). These characteristics can be defined as asymptotic average rates, they are independent of the initial conditions, and 
therefore they do comprise an invariant measure of attractor. Saying simply, the Lyapunov's exponents are the parameters to detect whether the system is chaotic or not.

Another important characteristics, namely, the Kolmogorov entropy $K_{\text {ent }}$ measures the average rate at which information about the state is lost with time. According to the definition, the Kolmogorov entropy can be determined as the sum of the positive Lyapunov's exponents.

The estimate of the dimension of the attractor is provided by the Kaplan and York conjecture:

$$
d_{L}=j+\frac{\sum_{\alpha=1}^{j} \lambda_{\alpha}}{\left|\lambda_{j+1}\right|},
$$

where $j$ is such that $\sum_{\alpha=1}^{j} \lambda_{\alpha}>0$ and $\sum_{\alpha=1}^{j+1} \lambda_{\alpha}<0$, and the Lyapunov's exponents $\lambda_{\alpha}$ are taken in descending order.

There are a few approaches to computing the Lyapunov's exponents. One of them computes the whole spectrum and is based on the Jacobi matrix of system. In this work we use an advanced algorithm with fitted map with higher order polynomials. To calculate the spectrum of the Lyapunov's exponents, one could determine the time delay $\tau$ and embed the data in the four-dimensional space. In this point it is very important to determine the Kaplan-York dimension and compare it with the correlation dimension, defined by the Grassberger-Procaccia algorithm].

As a rule, the calculational results of the state-space reconstruction are highly sensitive to the length of data set (i.e. it must be sufficiently large) as well as to the time lag and embedding dimension correctly determined.

Indeed, there are limitations on the applicability of chaos theory for observed (finite) dynamical variable series arising from the basic assumptions that these series must be infinite. A finite and small data set may probably result in an underestimation of the actual dimension of the process. The details of the computational procedures and algorithms can be also found in Refs. [27-46].

\section{Nonlinear dynamics of the chaotic laser diode: Some results and conclusions}

Below we present the results of of computing the dynamical and topological invariants of the nonlinear dynamics of the chaotic laser diode system with an additional optical injection According to [1], the dynamics of this system can be described by a set of rate equations for the slave laser electric complex amplitude $F$ and carrier density $n$, correspondingly and is represented as follows:

$$
\frac{d F}{d t}=\frac{1+i \beta}{2}\left\{\frac{g\left(n-n_{0}\right)}{1+\delta|F|^{2}}-\tau_{p}^{-1}\right\} F+
$$

$$
\frac{k_{f}}{\tau_{i}} F(t-\tau) \cdot \exp [-i 2 \pi \eta \tau]+\frac{k_{i}}{\tau_{i}} F_{j} \exp [i \Delta \eta t],
$$

$\frac{d n}{d t}=\frac{i}{q V}-\frac{n}{\tau_{N}}-\frac{g\left(n-n_{0}\right)}{1+\delta|F|^{2}}|F|^{2}+G(n)$

where $k_{f}$ and $k_{\mathrm{j}}$ denote the feedback and injection strength, the amplitude of injection laser $\left|F_{\mathrm{j}}\right|$ is equal to that of the solitary slave laser, and $\Delta \eta=\eta_{j}-\eta_{s}$ is the detuning between the injection and the slave lasers. The feedback delay $\tau=20$ ns is set in the experimental setup [1]. As the input data for the solving the rate equations system the numerical values of the parameters have been used as follows (see more details in Ref. [1]): transparency carrier density $\mathrm{n}_{0}=0.455 \times 10^{6} \mathrm{~m}^{-3}$, threshold current $\mathrm{i}_{\mathrm{th}} \mathrm{r}=22 \mathrm{~mA}$, differential gain $g=1.414 \times 10^{-3}$ $\mu \mathrm{m}^{3} \mathrm{~ns}^{-1}$, the carrier lifetime $\tau_{N}=2.5 \mathrm{~ns}$, photon lifetime $\tau_{p}=1.17 \mathrm{ps}$, round-trip time in laser intracavity $\tau_{i}=7.38 \mathrm{ps}$, the linewidth enhancement factor $\beta=5.0$, gain saturation parameter $\delta=5 \times 10^{-3} \mu^{3}$ and active layer volume $V=324 \mathrm{~m}^{3}$; the simulated slave laser is biased at $1.7 \mathrm{i}_{\mathrm{thr}}$ with $5.2 \mathrm{GHz}$ modulation bandwidth.

According to data [1], under $k_{\mathrm{j}}=0$, a growth of the parameter $k_{f}$ results in a perioddoubling bifurcation route to chaos, followed 
by a reversed route out of chaos. More exatly, a chaos is realized in the region about 0.04-0.16 of $k_{f}$ and bandwidths are about 4.0-6.2 GHz. The rate equations systems has been numerically solved and the corresponding time series for amplitude and density are obtained. The concrete step is an analysis of the corresponding time series with the $\mathrm{N}=\cdot 10^{4}$ and $\Delta t=2 \cdot 10^{-3} \mathrm{~ns}$. It is very important to declare that the dynamics of the chaotic laser diode system with an additional optical injection has the elements of a deterministic chaos (the strange attractor). In Table 1 we present the computational values of the correlation dimension $d_{2}$, the Kaplan-York attractor dimension $\left(d_{L}\right)$, the Lyapunov's exponents $\left(\lambda_{i}\right)$, Kolmogorov entropy $\left(\mathrm{K}_{\text {entr }}\right)$, the Gottwald-Melbourne parameter.

Table 1 Correlation dimension $d_{2}$, Lyapunov's exponents $\left(\lambda_{i}, i=1,2\right)$, Kaplan-York attractor dimension $\left(d_{L}\right)$, Kolmogorov entropy $\left(\mathrm{K}_{\mathrm{entr}}\right)$,

Gottwald-Melbourne parameter $K_{\mathrm{GW}}$

\begin{tabular}{|c|l|c|}
\hline $\mathrm{d}_{2}$ & \multicolumn{1}{|c|}{$\lambda_{1}$} & $\lambda_{2}$ \\
\hline 2.94 & 0.358 & 0.096 \\
\hline $\mathrm{d}_{\mathrm{L}}$ & $\mathrm{K}_{\text {entr }}$ & $\mathrm{K}_{\mathrm{GW}}$ \\
\hline 2.80 & 0.454 & 0.94 \\
\hline
\end{tabular}

To conclude, the values of the dynamical and topological invariants (the correlation, Kaplan-York dimensions, the Lyapunov's exponents etc) for the dynamics of the chaotic laser diode system with an additional optical injection are computed. In particular, the first two Lyapunov's exponents are positive. These data indicate on emerging dynamical chaos elements in the laser diode system dynamics.

\section{References}

1. Wang A.-B, , Wang Y.-C., Wang J.-F., Route to broadband chaos in a chaotic laser diode subject to optical injection. Optics Letters. 2009, 34(8), 1144-1146.

2. Pavlov E.V., Ignatenko A.V., Krianov S.V., ,Mashkantsev A.A., Dynamical and topological invariants of $\mathrm{PbO}$ dynamics in a resonant electromagnetic field. Photoelectronics. 2019, 28, 121-126.

3. Zhang C.; Katsouleas T.; Joshi C. Harmonic frequency generation \& chaos in laser driven molecular vibrations. In Proc. of Short-wavelength Physics with Intense Laser Pulses, San-Diego. 1993.

4. Berman, G.; Bulgakov, E.; Holm, D. Nonlinear resonance and dynamical chaos in diatomic molecule driven by a resonant IR field. Phys. Rev. A 1995, 52, 3074

5. Glushkov, A.V. Spectroscopy of atom and nucleus in a strong laser field: Stark effect and multiphoton resonances. $J$. Phys.: Conf. Ser. 2014, 548, 012020.

6. Ignatenko A., Buyadzhi A., Buyadzhi V., Kuznetsova, A.A., Mashkantsev, A.A., Ternovsky E. Nonlinear chaotic dynamics of quantum systems: molecules in an electromagnetic field. Adv. Quant Chem. 2019, 78, 149-170.

7. Glushkov, A., Buyadzhi, V., Kvasikova, A., Ignatenko, A., Kuznetsova, A., Prepelitsa, G., Ternovsky, V. Non-Linear chaotic dynamics of quantum systems: Molecules in an electromagnetic field and laser systems. In: Quantum Systems in Physics, Chemistry, and Biology. Springer, Cham. 2017, 30, 169-180

8. Mashkantsev, A. A. ; Ignatenko, A.V. ; Kirianov, S.V. ; Pavlov, E.V. Chaotic dynamics of diatomic molecules in an electromagneic field. Photoelectronics. 2018, 27, 103-112.

9. Glushkov A., Ternovsky V., Buyadzhi V, Prepelitsa G. Geometry of a relativistic quantum chaos: New approach to dynamics of quantum systems in electromagnetic field and uniformity and charm of a chaos. Proc. Int. Geom. Center. 2014, 7(4), 60-71.

10. Glushkov A.V.; Ivanov, L.N. DC strongfield Stark effect: consistent quantummechanical approach. J. Phys. B: At. Mol. Opt. Phys. 1993, 26, L379-386.

11. Ignatenko, A.; Buyadzhi ,A.; Buyadzhi, V.; Kuznetsova,A.; Mashkantsev, A.; Ternovsky E. Nonlinear chaotic dynamics of quantum systems: molecules in an 
electromagnetic field. Adv. Quant. Chem. 2019, 78, 149-170.

12. Glushkov, A.V. True effective molecular valency Hamiltonian in a logical semiempricial theory. Journal of Structural Chem. 1988, 29(4), 495-501.

13. Glushkov, A.V. Operator Perturbation Theory for Atomic Systems in a Strong DC Electric Field. In Advances in Quantum Methods and Applications in Chemistry, Physics, and Biology,; Hotokka, M., Brändas, E., Maruani, J., Delgado-Barrio, G., Eds.; Springer: Cham, 2013; 27, pp 161-177.

14. Malinovskaya, S.V.; Glushkov, A.V.; Khetselius, O.Yu.; Svinarenko, A.A.; Mischenko, E.V.; Florko, T.A. Optimized perturbation theory scheme for calculating the interatomic potentials and hyperfine lines shift for heavy atoms in the buffer inert gas. Int. J. Quant. Chem. 2009, 109(4), 3325-3329.

15. Glushkov A; Khetselius O; Malinovskaya S. Optics and spectroscopy of cooperative laser-electron nuclear processes in atomic and molecular systems - new trend in quantum optics. Europ. Phys. Journ. ST 2008, 160, 195-204.

16. Glushkov, A.V.; Khetselius, O.Yu.; Malinovskaya, S.V. Spectroscopy of cooperative laser-electron nuclear effects in multiatomic molecules. Molec. Phys. 2008, 106, 1257-1260.

17. Danilov, V., Kruglyak, Y., Pechenaya, V. Electron density-bond order matrix and the spin density in the restricted CI method. Theor. Chim Acta. 1969, 13(4), 288-296.

18. Danilov, V., Kruglyak, Y., Kuprievich, V., Ogloblin, V. Electronic aspects of photodimerization of the pyrimidine bases and of their derivatives. Theor. Chim.Acta. 1969, 14(3), 242-249.

19. Gottwald, G.A. ; Melbourne, I. Testing for chaos in deterministic systems with noise. Physica D. 2005, 212, 100-110.

20. Abarbanel, H.; Brown, R.; Sidorowich, $\mathrm{J}$; Tsimring, L. The analysis of observed chaotic data in physical systems. Rev. Mod. Phys. 1993, 65, 1331- 1392.
21. Packard, N.; Crutchfield, J; Farmer, J.; Shaw, R. Geometry from a time series Phys. Rev. Lett. 1988, 45, 712-716.

22. Kennel, M.; Brown, R.; Abarbanel, H. Determining embedding dimension for phase-space reconstruction using a geometrical construction. Phys. Rev. A. 1992, 45, 3403-3412.

23. Gallager, R. Information theory and reliable communication. N.-Y., 1986.

24. Grassberger, P. ; Procaccia, I. Measuring the strangeness of strange attractors. Physica D. 1983, 9, 189-208.

25. Theiler, J.; Eubank, S.; Longtin, A.; Galdrikian, B.; Farmer, J. Testing for nonlinearity in time series: The method of surrogate data. Phys.D. 1992, 58, 7794.

26. Sano, M.; Sawada, Y. Measurement of Lyapunov spectrum from chaotic time series. Phys.Rev.Lett. 1995, 55, 1082.

27. Glushkov, A.V. Methods of a Chaos Theory. OSENU: Odessa, 2012.

28. Glushkov, A.V.; Khetselius, O.Yu.; Brusentseva, S.V.; Zaichko, P.A.; Ternovsky, V.B. Studying interaction dynamics of chaotic systems within a nonlinear prediction method: Application to neurophysiology In Advances in Neural Networks, Fuzzy Systems and Artificial Intelligence, Series: Recent Advances in Computer Engineering; Balicki, J., Ed.; WSEAS Press: Gdansk, 2014; Vol 21, pp 69-75.

29. Glushkov, A.; Prepelitsa, G.; Svinarenko, A.; Zaichko, P. Studying interaction dynamics of the non-linear vibrational systems within non-linear prediction method (application to quantum autogenerators) In Dynamical Systems Theory; Awrejcewicz, J., Kazmierczak, M., Olejnik, P., Mrozowski, J., Eds.; Łódz, 2013; Vol T1, pp 467-477.

30. Khetselius, O. Forecasting evolutionary dynamics of chaotic systems using advanced non-linear prediction method In Dynamical Systems Applications; Awrejcewicz, J., Kazmierczak, M., Olejnik, P., Mrozowski, J., Eds.; Łódz, 2013; Vol T2, pp 145-152. 
31. Khetselius, O.; Brusentseva, S.; Tkach, T. Studying interaction dynamics of chaotic systems within non-linear prediction method: Application to neurophysiology In Dynamical Systems Applications, Awrejcewicz, J, Kazmierczak, M, Olejnik, P., Mrozowski, J., Eds.; Łódz, 2013; T2, pp 251-259.

32. Glushkov, A.; Khetselius, O.; Brusentseva, S.; Duborez, A. Modeling chaotic dynamics of complex systems with using chaos theory, geometric attractors, quantum neural networks. Proc Int. Geom. Center. 2014, 7(3), 87-94.

33. Glushkov, A.V.; Bunyakova, Yu.Ya.; Zaichko, P.A. Geometry of Chaos: Consistent combined approach to treating chaotic dynamics atmospheric pollutants and its forecasting. Proc. Intern. Geom. Center. 2013, 6(3),6-14.

34. Khetselius, O.Yu.; Florko, T.A.; Svinarenko, A.A.; Tkach, T.B. Radiative and collisional spectroscopy of hyperfine lines of the Li-like heavy ions and $\mathrm{Tl}$ atom in an atmosphere of inert gas. Phys. Scripta. 2013, T153, 014037

35. Khetselius, O.Yu. Relativistic calculating the hyperfine structure parameters for heavy-elements and laser detecting the isotopes and nuclear reaction products. Phys. Scripta. 2009, T135, 014023.

36. Svinarenko, A.A. Study of spectra for lanthanides atoms with relativistic manybody perturbation theory: Rydberg resonances. J. Phys.: Conf. Ser. 2014, 548, 012039

37. Khetselius, O.Yu. Atomic parity nonconservation effect in heavy atoms and observing $\mathrm{P}$ and PT violation using NMR shift in a laser beam: To precise theory. J. Phys.: Conf. Ser. 2009, 194, 022009.

38. Glushkov, A.; Loboda, A.; Gurnitskaya, E.; Svinarenko, A. QED theory of radiation emission and absorption lines for atoms in a strong laser field. Phys. Scripta. 2009, 135, 014022.
39. Glushkov A.V.; Ivanov, L.N. DC strongfield Stark effect: consistent quantummechanical approach. J. Phys. B: At. Mol. Opt. Phys. 1993, 26, L379-386.

40. Khestelius, O.Yu. Hyperfine structure of atomic spectra. Astroprint: Odessa, 2008.

41. Glushkov A.; Khetselius O.; Svinarenko A. Theoretical spectroscopy of auto ionization resonances in spectra of lanthanide atoms. Phys. Scr. 2013, T153, 014029.

42. Glushkov A. Spectroscopy of cooperative muon-gamma-nuclear processes: Energy and spectral parameters J. Phys.: Conf. Ser. 2012, 397, 012011

43. Khetselius O Spectroscopy of cooperative electron-gamma-nuclear processes in heavy atoms: NEET effect. J. Phys.: Conf. Ser. 2012, 397, 012012.

44. Ivanova, E., Ivanov, L., Glushkov, A., Kramida, A. High order corrections in the relativistic perturbation theory with the model zeroth approximation, Mg-Like and Ne-Like Ions. Phys. Scr. 1985, 32, 513-522

45. Glushkov, A.V.; Khetselius,O.Yu.; Svinarenko,A.A.; Buyadzhi, V.V. Spectroscopy of autoionization states of heavy atoms and multiply charged ions (Odessa: TEC) -2015.

46. Glushkov, A.V.; Buyadzhi, V.V.; Ponomarenko, E.L. Geometry of Chaos: Advanced approach to treating chaotic dynamics in some nature systems. Proc. Int. Geom. Center. 2014 7(1),24-30.

47. Glushkov A., Khetselius O., Kruglyak Yu., Ternovsky V. Calculational Methods in Quantum Geometry and Chaos theory. P.3. Odessa, 2014.

48. Glushkov A., Khetselius O., Svinarenko A, Buyadzhi V. Methods of computational mathematics and mathematical phys. P.1.TES, Odessa, 2015. 
Kirianov S.V., Mashkantsev A.A., Bilan I.I., Ignatenko A.V.

\section{DYNAMICAL AND TOPOLOGICAL INVARIANTS OF NONLINEAR DYNAMICS OF THE CHAOTIC LASER DIODES WITH AN ADDITIONAL OPTICAL INJECTION}

Summary. Nonlinear chaotic dynamics of the of the chaotic laser diodes with an additional optical injection is computed within rate equations model, based on the a set of rate equations for the slave laser electric complex amplitude and carrier density. To calculate the system dynamics in a chaotic regime the known chaos theory and non-linear analysis methods such as a correlation integral algorithm, the Lyapunov's exponents and Kolmogorov entropy analysis are used. There are listed the data of computing dynamical and topological invariants such as the correlation, embedding and Kaplan-Yorke dimensions, Lyapunov's exponents, Kolmogorov entropy etc. New data on topological and dynamical invariants are computed and firstly presented.

Key words: Chaotic dynamics, laser diodes, dynamical and topological invariants

PACS 31.15.-p; 33.20.-t

Кирьянов С.В., Машканцеев А.А., Билан И.И., Игнатенко А.В.

\section{ДИНАМИЧЕСКИЕ И ТОПОЛОГИЧЕСКИЕ ИНВАРИАНТЫ НЕЛИНЕЙНОЙ ДИНАМИКИ ХАОТИЧЕСКИХ ЛАЗЕРНЫХ ДИОДОВ С ДОПОЛНИТЕЛЬНОЙ ОПТИЧЕСКОЙ ИНЪЕКЦИЕЙ}

Резюме. Нелинейная хаотическая динамика хаотических лазерных диодов с дополнительной оптической инжекцией рассчитывается в рамках модели скоростных уравнений, в частности, модели, основанной на системе скоростных уравнений для комплексной электрической амплитуды лазера и плотности. Для моделирования динамики в хаотическом режиме используются известные методы нелинейного анализа и теории хаоса, в т.ч., метод корреляционного интеграла, анализ на основе показателей Ляпунова, энтропии Колмогорова и др. Представлены данные вычисления динамических и топологических инвариантов, в т.ч., размерностей вложения, корреляционной, КапланаЙорка, показателей Ляпунова, др.

Ключевые слова: хаотическая динамика, лазерные диоды, динамические и топологические инварианты

PACS 31.15.-p; 33.20.-t

Кір'янов С.В., Машканцев О.А., Білан I.І., Ігнатенко Г.В.

\section{ДИНАМІЧНІ І ТОПОЛОГІЧНІ ІНВАРІАНТИ НЕЛІНІЙНОӤ ДИНАМИКИ ХАО- ТИЧНИХ ЛАЗЕРНИХ ДІОДІВ 3 ДОДАТКОВОЮ ОПТИЧНОЮ ІНЖЕКЦІЮ}

Резюме. Нелінійна хаотична динаміка хаотичних лазерних діодів з додатковою оптичної інжекцією розраховується в рамках моделі швидкісних рівнянь, зокрема, моделі, заснованої на системі швидкісних рівнянь для комплексної електричної амплітуди лазера і густини носіів. Для аналізу динаміки системи в хаотичному режимі використані методи нелінійного аналізу та теорії хаосу, у т.ч., метод кореляційного інтеграла, аналіз на основі показників Ляпунова, ентропії Колмогорова т.і. Надані дані обчислення динамічних і топологічних інваріантів: розмірностей кореляційної, вкладення, КапланаЙорка, показників Ляпунова, та інших.

Ключові слова: хаотична динаміка, лазерні діоди, динамічні та топологічні інваріанти 